\title{
Reflections on How to Improve Educational Quality of the JM Graduate Students
}

\author{
Ying LIU \\ Capital University of Economics and Business, Beijing, China \\ 441586900@qq.com
}

Keywords: Juris Master (JM), Educational quality, Problems, Improvement.

\begin{abstract}
Currently, China's national enrollment policies are showing an increasing preference for professional degrees. This has inevitably led to expansion of the enrollment scale of Juris Master (JM) graduate students. Nevertheless, the current JM educational quality in China has been worrying. Based on a thorough reflection on the educational process of JM, the author points out the status and existing problems of JM education. Meanwhile, the educational status of top-notch legal talents in three countries, such as the United States, Germany and Japan, is studied. On that basis, several suggestions are proposed for improvement of JM educational quality in China. It is hoped that this research can help bring up more top-notch and hands-on legal talents for the country and society. Juris Master (JM) education, after being launched in China in 1995, has been developing for more than two decades, succeeding in bringing up a large batch of outstanding legal talents. China's original intention of offering JM education in colleges and universities was to respond to the increasingly extensive scope of judicial activities, the increasingly complex legal issues, and an increasingly higher requirement of legal talents. Therefore, at that time, China was faced with the imperative to develop a large batch of top-notch and hands-on legal talents. Before 2009, China's law education was made up of Master of Laws programs and Juris Master programs, the latter of which referred to graduate students not studying Law during the undergraduate period. Things have been changed after 2009. According to the notice of the Ministry of Education of the PRC, Law is introduced as a new academic program, which brings up students majoring in Law in both undergraduate and graduate period. "JM" programs mentioned in this paper incorporates not only the traditional Juris Master programs for students not majoring in Law during the undergraduate period, but also the later-developed Juris Master programs for students majoring in Law in both undergraduate and graduate period.
\end{abstract}

\section{Status of JM Education in China}

\section{Vigorous Efforts at the National Level to Develop JM Graduate Education}

In 2013, the Ministry of Education of the PRC, China National Development and Reform Commission and Ministry of Finance of the PRC jointly promulgated the Opinions on Deepening Graduate Education Reform. This document provides suggestions for full implementation of the $18^{\text {th }}$ CPC National Congress and the China National Medium-and Long-term Educational Reform and Development Programme (2010 - 2020), further improvement of graduate educational quality as well as deepening of the graduate education reform. In this document, suggestions can also be found for how to develop education for professional master degrees, which can mainly be boiled down into the following aspects. First, optimize the talent development type and structure, actively promote the graduate education for professional master degrees, and shift the talent development structure and type from dominance of academic degrees to coordinated development between academic degrees and professional degrees. Second, separate postgraduate entrance examinations for academic degree candidates from those for professional degree candidates. Third, built a professional degree graduate education model oriented towards improvement of occupational abilities. Fourth, develop talents with comprehensive qualities required by different positions in the workplace, form an industry-university combined development model, enhance the practice base construction, strengthen development of hands-on abilities and entrepreneurial abilities of graduate 
students pursuing professional degrees, and actively promote organic connection between professional academic degrees and professional qualifications.

In interpreting the Opinions on Deepening Graduate Education Reform, personnel from the Ministry of Education also mentioned that the graduate education type and structure in China can hardly meet needs of social development. Therefore, it is necessary to stabilize the scale of graduates pursuing academic degrees, actively develop the professional master degree programs and promote coordinated development between academic degree and professional degree graduate education programs.

In fact, worldwide, the percentage of professional degrees has been rising. In the United States, the percentage of students with the professional master degree accounted for more than $55 \%$ of students with the master degree even in the 1990s. In Britain, annually, around $75 \%$ of graduates are conferred with the master profession degree. The figure for France is around 69\%, suggesting that the professional master degree education has dominated France's graduate education system.

Since 2009, China has started to expand the enrolment of students pursuing professional master degrees. In 2009, there were only 40,000 students signing up for the entrance examinations for professional degree programs, many of whom were students failed to be admitted by academic degree programs and got transferred to professional degree programs. In the graduate entrance examinations of 2013, the number of students signing up for professional degree programs reached 430,000 , accounting for one fourth of the total candidates. In 2016, the figure soared up to 850,000, which was close to 920,000, the number of students signing up for academic degree programs.

\section{Gradual Expansion of the Enrolment Scale of China's JM Programs}

The Chinese government has been paying increasing attention to professional master degree education. The Ministry of Education has made it clear to give more preference to professional master degree programs. This means expansion of the enrolment scale of China's JM programs to be inevitable.

Compared with Master of Laws programs, JM programs attach more importance to hands-on skills. The latter is an attempt to meet needs of social and enterprise development. An increasing number of JM graduates have been working in courts, procuratorates, law firms, legal affairs departments and so on after stepping in society. These talents have alleviated the talent shortage of legal practice departments and contribute to progress of China's rule of law. Meanwhile, talents brought up by JM programs have been widely recognized by employers. The Fourth Session of the $18^{\text {th }}$ CPC Central Committee passed the decision on fully promoting rule of law. This fully demonstrates China's determination to govern the country by rule of law. To a country following rule of law, there is a huge demand for hands-on legal talents.

After surveying the enrolment situations of different colleges and universities, the author observes that many colleges and universities have increased the enrolment percentage of JM programs, making it close to the enrolment scale of Master of Laws programs. In some colleges and universities, the number of students admitted by JM programs is higher than the number of students admitted by Master of Laws programs. The prosperity of JM programs cannot be separated from the national government's growing attention to professional master degree programs and the accurate positioning of development goals of professional master degree programs.

Development of professional degree programs has been mentioned in the Third Plenary Session, Fourth Plenary Session, Fifth Plenary Session and Sixth Plenary Session of the $18^{\text {th }}$ CPC Central Committee, major speeches by General Secretary Xi Jinping (particularly the speech made by General Secretary Xi Jinping on an inspection tour to the China University of Political Science and Law) as well as the ideological and political work conference on national institutions of higher learning. In order to implement the spirit delivered by the other meetings and speeches and to promote comprehensive reform of graduate education, the State Council Academic Degree Committee forwarded the Guide to the Educational Plan of the Academic Degree of JM, which clearly mentions goals of JM education. According to the document, JM candidates (students not studying Law during undergraduate years) should be developed into top-notch, compound and 
applied legal talents with both ability and political integrity to provide legislation, judicial, administrative enforcement and legal services for different trades and industries. The same requirement is also put forward for JM candidates (students studying Law during undergraduate years).

\section{Urgency to Improve the JM Educational Model}

As the enrolment scale of JM programs keeps on expanding, there has been a higher requirement of JM educational quality. Comparatively, education for law of masters has a profound history. Previously, the Chinese government also emphasized a lot on education of law of masters. As a result, for a long time, priority was given to education of law of masters, while JM education lacked a systematic research and referred to the educational model of law of masters. Nowadays, things have been changed. JM programs have expanded their enrolment scale to cater to an increasing social demand for legal talents. The previous educational model of JM programs designed by making reference to that of Law of Masters programs is obviously unsuitable. Specialized and systematic research should be carried out based on characteristics of JM education so as to improve educational quality of JM programs.

The educational process of JM programs involves multiple aspects. Apart from hard requirements, such as classroom teaching, specialty practice and graduation paper, it also covers soft requirements, such as the educational concept, faculties, scientific research projects, professional ethics, psychological health, legal thinking, dual-supervisor system, mock court, debate competitions, legal clinics, academic atmosphere construction, academic lectures, academic forums, policies on "teaching assistant, research assistant and administration assistant", scholarships, innovation ability, and career guidance.

\section{Problems Facing Education of JM Programs in China}

\section{A Low Recognition Degree of JM Programs among Students and Society}

The society does not have a high recognition of positioning and educational quality of JM programs. Nor do students themselves. Consequently, JM graduates are sometimes faced with "employment discrimination", and some employers usually show prejudice against JM graduates.[1] This has greatly dampened students' enthusiasm to sign up for JM programs and reduce the charm of JM programs to outstanding students.

Statistics show that, apart from several famous law schools, the JM programs of most colleges and universities in China are not applied to by students as the first choice. Thus, JM programs of these colleges and universities usually fail to accomplish their enrolment goal annually. Under the condition, students applying to academic degrees are offered a choice to get transferred to JM programs. The measure, though beneficial to improvement of student sources, has some defects not to be ignored. On the one hand, the enrolment rate of students applying to JM programs as the first choice is low. On the other hand, students transferred to JM programs are not interested in JM programs. They accept the transfer simply because there are no places for them in academic degree programs. In this way, these students have a low recognition degree of JM education, and the JM programs can hardly arouse their interest in learning. All this will directly influence students' learning effects, attitude towards learning and construction of the academic atmosphere.

In China, though candidates pursing Master of Laws are all developed according to the educational model for academic degree programs, most students tend to engage in legal practice after graduation. This leads to a high degree of consistency between the occupational direction of Master of Laws and JM. However, an embarrassing situation is that JM programs have not yet been widely recognized by society. Characteristics, advantages, and educational significance of JM programs have not been fully reflected in the implementation process.

\section{Unreasonable Curriculum Setting and Teaching Style}

The curriculum setting and teaching style of some colleges and universities are still quite traditional, 
with teaching of theoretical knowledge at the core. Worse still, there are no striking differences between JM curriculum and curriculum for undergraduates majoring in Law. As to the teaching style, classroom teaching and theoretical teaching are still dominant. The occupational characteristics of JM programs are ignored. In fact, knowledge of legal qualities and practice skills as well as the ability to solve practical problems are what matters most to JM programs. However, the current situation is that there is a weak link between the curriculum setting of most JM programs and the needs of social and economic development. Therefore, it is imperative to adjust the curriculum structure.

\section{Dual-supervisor System Reduced to Formalism}

In response to the wave of JM educational reform, many Chinese colleges and universities have introduced the system of inviting supervisors in and off the campus to jointly develop students. This sounds a favorable system. Pitifully, during the practical implementation process, supervisors off the campus exist in name only. They seldom take part in teaching activities. Particularly, some colleges and universities are in favor of employing leaders from political legal departments to serve as supervisors off the campus. These supervisors are busy with their own work. They can hardly find time to fully devote themselves to guiding and teaching JM students. Supervisors off the campus cannot be just regarded as a bond between schools and relevant political legal departments. Nor should it be reduced to a means to add glories to some leaders. The dual-supervisor system should play its role in the process of JM education. However, there has not yet been a definite answer to how to fully implement the system.

In the Opinions on Deepening Reform of Graduate Education, the necessity to improve supervisors' teaching abilities and the accountability mechanism with teachers as the first person responsible is clearly pointed out. In fact, students are often in a position to help supervisors collect materials and ran errands, such as applying for reimbursements, for teachers. On the contrary, supervisors spend little time thinking about how to improve students' academic or hands-on abilities.

\section{Lack of Hands-on Abilities among JM Graduates}

According to the Guide to the Educational Plan of the Academic Degree of JM issued in 2017, students either majoring in master of laws programs (for students majoring in Law both in undergraduate and graduate years) and JM programs (for students not majoring in Law during undergraduate years) should both comprehensively grasp professional knowledge of law; solve practical legal issues via a legal thinking; get familiar with methods to interpret laws and develop the ability of legal reasoning in handling specific cases; learn major procedures of litigation and gain a good understanding of legal agency and defense services; get adept at organizing and managing non-litigious legal practices and legal affairs; and increase proficiency in preparing legal documents.

To bring up top-notch legal talents in line with development needs of the modern society is the goal and direction of China's JM programs. Undoubtedly, textbooks and classroom teaching are important channels for students to acquire basic theoretical knowledge, but a series of professional legal practices is also inevitable. In the current stage, JM programs usually ignore the importance of practice, or the goal has been integrated into JM programs, but a proper way to realize the goal has not yet been found out. This has hindered realization of the goal to bring up top-notch and hands-on legal talents.

\section{Improvement of the Teaching Staff}

Currently, the teaching staff responsible for JM programs and Master of Laws programs are generally the same. More often than not, Chinese colleges and universities assign the same teaching staff to give lessons to the two kinds of students at the same time. In doing so, colleges and universities ignore a major difference between the goal of JM programs and Master of Laws, that is, the former aims at bringing up talents with hands-on abilities, while the latter is committed to developing research-oriented talents. The energy and time of a teaching staff is usually limited. It is 
impossible for him or her to accommodate to teaching characteristics of the two different programs. Besides, JM education started late in China. Its educational mechanism has not yet been so complete as that of Master of Laws. As a result, JM education usually refers to the educational model of Master of Laws, thus losing its own educational characteristics.

When deciding whether to give lessons, teachers give too much consideration to the requirement of workload. If their workload has already met the requirement, they can stop setting up any other new courses. If their workload has not yet met the requirement, they will be forced to teach some courses which they are not familiar with. The mechanism cannot effectively stimulate teachers' enthusiasm to teach, thus undermining the teaching quality. In the teaching staff structure, the percentage of teachers with rich experience in law practice is too low. The structural demand contradiction has been a major hindrance to realization of bringing up legal talents with hands-on abilities.

\section{Experience of Other Countries in Bringing up Top-notch Legal Talents}

\section{Implications of the American Legal Talent Education to China}

The legal education that American students are receiving is actually graduate education with Juris Doctor (JD) at the core. It is a post-undergraduate education. Its educational goal is clear, which is to bring up lawyers. It also indirectly brings up judges and procurators, which are usually selected from outstanding lawyers. The American Bar Association once pointed out that legal talents graduating from American law schools should be equipped with abilities in three aspects, namely knowledge of law and legal institutions, basic skills and ability to effectively apply law knowledge and skills to practical cases. In order to materialize the above three abilities, American law schools have attached great importance to students' ability to apply law to solve real-life problems in terms of their curriculum setting. The emphasis of American legal education on social practices is referential for China to cope with the structural imbalance - overemphasis on theories and ignorance of practice - in its JM education or even its whole legal education system.

\section{Implications of the German Legal Talent Education to China}

America follows the common law system. Its legal educational model is hard to get implemented in China which adopts the civil law system. Germany is a country with a long history of implementing the civil law system, so its experience in developing legal education can provide favorable reference for China. On March 21, 2002, Germany passed the Law on Reform of Legal Education, which focuses on changing the model of legal education and strengthening of development of professional ethics and skills among law students. Since then, Germany's legal education no longer aims at developing judges only. Its goal is expanded to develop all law-related talents, particularly lawyers. Hence, Germany's legal education is also oriented towards vocational education.

Since 2003, the German law schools have been entrusted to hold judicial examinations. 30\% of law students' test scores during their undergraduate period constitute part of the final scores of judicial examinations. Besides, only legal talents having received legal education in colleges or universities are qualified for the judicial examinations. Also, Germany has the requirement on how many times students can participate in these examinations. For example, if a student fails to pass the judicial examinations the first time, he or she just has one opportunity to participate in make-up examinations. This forces students to get fully prepared for the examinations rather than waste the opportunity to be a professional in the law industry. More importantly, the quality and abilities of legal professionals can be fundamentally guaranteed. Similarly, China has also stressed practicality in its JM education, but the legal talents thus brought up are still far from being satisfying. Thus, Chin can learn the concept of closely linking legal education with vocational education from Germany.

\section{Implications of the Japanese Legal Talent Education to China}

In 2004, Japan started to implement the system of university council for law subjects, thus leading 
to formation of the process-oriented legal talent development mechanism made up of the link of undergraduate education (law or non-law majors), law university council education, election through judicial examinations, and study in judicial advanced research institutes. The system has been an important part of Japan's judicial system reform in the $21^{\text {st }}$ century. Establishment of the system has helped Japan shifted its law educational model from orientation towards development of legal qualities to orientation towards development of professional ethics. The purpose of Japan to set up the system of university council for law subjects is to bring up law professionals. It provides not only theoretical education, but also education of professional ethics required by development of experts in the field of law practice.

Following the implementation of the system of university council for law subjects, supply of adequate teaching staff becomes an issue of great concern. To address the concern, Japan has formulated law, stipulating the obligation of the national government to designate judges, procurators and lawyers to provide vocational education for students in the university council for law subjects. The system of university council for law subjects in Japan is different from China's JM education. Despite that, both aim at bringing up legal talents with hands-on abilities. The Japanese government's efforts made to improve law students' hands-on abilities, particularly promulgation of law to provide adequate teaching staff for schools, is worth China's reference.

\section{Suggestions for Improving the Educational Quality of JM Programs in China}

\section{Building a Scientifically Reasonable JM Curriculum System}

A complete curriculum system can lay a solid foundation for improvement of JM educational quality. To the end, the classroom structure should first be adjusted with the percentage and number of optional courses increased. If conditions allow, schools can also implement the joint development mechanism. During the teaching process, professionals with rich experience can be introduced to provide students with optional courses. These experts in legal practice can teach students how to write legal documents, analyze cases, etc.

Second, attention should be paid to improvement of teaching methods. On the basis of theoretical teaching, case study and practice-based teaching can be introduced to enrich the current teaching methods. The diverse teaching methods can better develop students' legal thinking and ability to solve legal problems and grasp basic practice methods. Mock court and legal clinic are two beneficial explorations. Mock court can be organized to enhance training of court trials. This is an effective means to develop students' interest in learning, allowing them to get familiar with procedures to handle cases. Meanwhile, students' ability to write legal documents and communicate with clients can be honed. Legal clinic can make up the gap of the didactic approach to further develop students' analysis and problem-solving ability. In this way, students can acquire professional skills in the law industry and effectively develop students' practical abilities and reasoning abilities.

Third, the educational concept of individualized teaching can be introduced to set up diverse development directions. During the process of JM education, most colleges and universities set up their characteristic modules and optional courses in accordance with their own development objectives and advantages. For example, more specialties can be provided, including lawyer affairs, corporate legal affairs, government legal affairs, foreign legal affairs, etc. All these academic directions are oriented towards practical applications, which can increase connection between JM education and professions in the law industry. This is also in line with the teaching objective oriented to social needs.

Fourth, courses related to professional ethics and moral ethics cannot be ignored. These courses can help firm up students' faith in professional ethics deep down inside. In this way, no matter when students are coping with tricky affairs, they can still stick to basic professional ethics.

Last but not least, a case library should be specially compiled for JM candidates. The case library should include not only classical cases, but also latest cases. By discussing cases, JM candidates can forge their legal thinking. 


\section{Giving Full Play to the Dual-supervisor System and the Role of the Campus Supervisor as the First Person Responsible}

It is imperative to set up the dual-supervisor system so as to improve JM's hands-on abilities and meet social requirements of JM graduates. For example, supervisors off the campus can be invited to lecture on hands-on abilities, supervise paper writing, provide internship guidance or advice on career planning. All in all, a proper approach should be found to enable supervisors off the campus to play a bigger role.

As to supervisors within the campus, the evaluation system should first be reformed. The Ministry of Education has suggested changing the separate evaluation mechanism of master supervisors' qualifications. Revolving around educational quality, supervisors in the campus should sharpen their awareness of closely linking their job with students' development. The life-long supervisor mechanism should be prevented. According to the annual enrolment needs and combining the subject characteristics, compliance with teachers' professional ethics, academic performance, scientific research projects and teaching quality, the number of supervisors and the number of graduate students every supervisor is in charge of can be pinned down. The student-supervisor two-way selection system should be improved with full respect show to the right of the supervisor and graduate student to choose each other freely. That supervisors are evaluated purely based on the number, influence factor and citations of papers published by them should be changed.Meanwhile, the supervisor accountability system should be strengthened. The supervisor within the campus should be the first person responsible, who is responsible for guiding students on attitude towards academic research and moral education, formulating and adjusting graduate students' development plan, recommending references for students, giving suggestions on how to choose courses, take part in practices and innovational activities, supervise students' scientific research and academic paper writing.

During the process of development, supervisors should not only fulfil duties stipulated by school regulations, but also pay attention to students' development of their abilities to learn autonomously, do research independently, and be innovational. To be competent to such a role, importance should be attached to development of supervisors' abilities to provide better guidance for students. On the one hand, training of supervisors should be enhanced. Opportunities should be created for supervisors to participate in academic exchange, visits to other universities and industrial practice. All these are channels for supervisors to improve their academic level. Meanwhile, supervisors' sense of responsibility and mission should be reinforced so that supervisors will realize their responsibility and thus devote more energy and time to developing graduate students.

\section{Strengthening Professional and Hands-on Abilities of JM Candidates}

Professional practice is an important link to realize the goal of developing JM graduates with hands-on abilities, which is also a bond between the theoretical learning and the acquisition of practical skills. In China, JM education and professions in the law industry have not yet been closely connected with each other. Vocational education should aim at bringing up talents with hands-on abilities. However, emphasis on theoretical learning and ignorance of practical operation have been a “chronic illness” of China’s JM programs, which has not yet been fully cured. Even if a student passes the judicial examinations, his or her hands-on abilities might still be lacking. In fact, almost every JM program requires students to seek internship experience. However, there are no monitoring mechanisms and effective ways of learning in the internship link. Most interns are responsible for sorting out files, taking down records of interrogation, delivering judicial documents, etc. All these tasks have little to do with application of professional knowledge. These internship opportunities have aroused students' dissatisfaction with internship effects.

The following efforts can be made to achieve better learning effects and improve students' practical abilities. On the one hand, schools should take the initiative to communicate with internship bases, suggesting them arrange students in different positions based on their strengths. Meanwhile, construction of internship bases should be diversified. The graduation direction of JM students after graduation should be fully taken into consideration. Cooperation with courts, 
procuratorates, and law firms is not the only choice for law schools. Partnership can be sought with enterprises to allow students to put their knowledge into practice in positions related to legal affairs. In this way, students' learning demands can be fully satisfied. Meanwhile, students should get fully prepared for what abilities are required by these positions and then work hard to strive for an all-around improvement of their ability to make their legal knowledge facilitate their handling of specific cases.

\section{Improving the Teaching Staff}

Improvement of the teaching staff is an important guarantee for high quality JM education. Currently, many law schools emphasize too much on students' scientific research level and professional title. Their teaching level is not quantitatively analyzed and directly reflected. This is why the teaching level of the teaching staff is usually ignored. In fact, survey shows that JM candidates care little about whether teachers have a high scientific research level and professional title. They are more interested in the rich theoretical knowledge, teaching experience and legal practice experience of teachers. 'To cater to students' needs, evaluation of teachers should be diversified. The burden of scientific research should be alleviated so that teachers will have more time and energy to explore how to improve their teaching level. On the other hand, more opportunities should be created for teachers to get involved in legal practices. Only in this way can teachers obtain latest cases and problem-solving abilities and share them with teachers. Third, supervisors outside the campus should be invited to give lectures irregularly so that students can directly interact with law professionals.

\section{Summary}

To sum up, under the background that the Chinese government is vigorously promoting professional master degree education, expansion of the JM educational scale has been an irresistible trend. Problems with the previous JM educational model designed by referring to that of Master of Laws programs have become increasingly prominent. Therefore, how to improve JM educational quality in China has become an issue requiring immediate attention. This research comes up with the following suggestions for development of JM education in China, namely optimizing the curriculum system, improving the dual-supervisor system, giving full play to the role of supervisors in the campus as the first person responsible, emphasizing on JM candidates' hands-on abilities, and improving the teaching staff. It is hoped that these suggestions can help bring up more top-notch legal talents with hands-on abilities for the country and society.

\section{References}

[1] Capital Higher Education Development Research Base of Beijing University of Aeronautics and Astronautics. University and Research Institute Jointly Cultivated Postgraduate Case Studies (2012)[M]. Peking University Press, 2014

[2] Ji Guang, Zhao Zongjiang. Research ideas and methods[M]. People's Medical Publishing House, 2016

[3] Qi Weixin, Li Xiangyan, Zhou Min. Research on postgraduate funding system——A case study of a provincial scientific research university[J].Accountants, 2017(11)

[4] Xia Qingyu. Some Suggestions on China's Higher Education and Research Work[J]. Daqing Social Sciences, 2018(1)

[5] Ye Siqiao. Postgraduate research activities and academic norms [M]. China Water Power Press, 2014 